\title{
A Single Amphetamine Infusion Reverses Deficits in Dopamine Nerve-Terminal Function Caused by a History of Cocaine Self-Administration
}

\author{
Mark J Ferris', Erin S Calipari', Jamie H Rose', Cody A Siciliano', Haiguo Sun', Rong Chen' and Sara R Jones*,I \\ 'Department of Physiology and Pharmacology, Wake Forest School of Medicine, Winston-Salem, NC, USA
}

\begin{abstract}
There are 1.6 million people who meet the criteria for cocaine addiction in the United States, and there are currently no FDA-approved pharmacotherapies. Amphetamine-based dopamine-releasing drugs have shown efficacy in reducing the motivation to self-administer cocaine and reducing intake in animals and humans. It is hypothesized that amphetamine acts as a replacement therapy for cocaine through elevation of extracellular dopamine levels. Using voltammetry in brain slices, we tested the ability of a single amphetamine infusion in vivo to modulate dopamine release, uptake kinetics, and cocaine potency in cocaine-naive animals and after a history of cocaine self-administration ( $1.5 \mathrm{mg} / \mathrm{kg} /$ infusion, fixed-ratio I, 40 injections/day $\times 5$ days). Dopamine kinetics were measured I and $24 \mathrm{~h}$ after amphetamine infusion $\left(0.56 \mathrm{mg} / \mathrm{kg}\right.$, i.v.). Following cocaine self-administration, dopamine release, maximal rate of uptake $\left(V_{\max }\right)$, and membrane-associated dopamine transporter (DAT) levels were reduced, and the DAT was less sensitive to cocaine. $A$ single amphetamine infusion reduced $V_{\text {max }}$ and membrane DAT levels in cocaine-naive animals, but fully restored all aspects of dopamine terminal function in cocaine selfadministering animals. Here, for the first time, we demonstrate pharmacologically induced, immediate rescue of deficits in dopamine nerveterminal function in animals with a history of high-dose cocaine self-administration. This observation supports the notion that the DAT expression and function can be modulated on a rapid timescale and also suggests that the pharmacotherapeutic actions of amphetamine for cocaine addiction go beyond that of replacement therapy.

Neuropsychopharmacology (20I5) 40, I826-1836; doi:I0.1038/npp.20I5.45; published online II March 2015
\end{abstract}

\section{INTRODUCTION}

The number of people addicted to cocaine in the United States has remained relatively stable over the past several decades and ranges between 1.0 and 1.7 million (Substance Abuse and Mental Health Services Administration (SAMHSA), 2008). In 2012, over half of this population sought treatment for their addiction to cocaine (Substance Abuse and Mental Health Services Administration (SAMHSA), 2008). The relatively stable prevalence of cocaine addiction despite large numbers seeking treatment is due, in part, to the fact that there is currently no FDA-approved pharmacotherapy for the treatment of cocaine addiction.

Some of the more promising pharmacotherapeutic agents from the basic and clinical research literatures are amphetamine-based dopamine releasers (Rush and Stoops, 2012). Dopamine releasers serve as replacement therapies for the dopamine elevating and primary reinforcing effects of cocaine (Rothman et al, 2006, 2008) and may acutely offset dopamine hypofunction observed in abstinent cocaine users.

*Correspondence: Dr SR Jones, Department of Physiology and Pharmacology, Wake Forest University School of Medicine, WinstonSalem, NC 27I57, USA, Tel: + I 3367165504 , Fax: + I 336716850 I, E-mail: srjones@wakehealth.edu

Received 17 December 2014; revised 4 February 2015; accepted 4 February 2015; accepted article preview online 18 February 2015
Indeed, cocaine-dependent humans exhibit reduced stimulated dopamine release (Volkow et al, 1997; Malison et al, 1999; Martinez et al, 2007) and reduced extracellular dopamine levels. Reduced extracellular levels and reduced stimulated release may be mechanistically related; however, changes in the function of the dopamine transporter (DAT) may also account for shifts in dopamine tone. Clinical and preclinical work demonstrate mixed results with respect to cocaine-induced changes in levels of the DAT, with the majority of investigations indicating increased DAT levels in cocaine-dependent or newly abstinent individuals (Narendran and Martinez, 2008; Little et al, 1993; Malison et al, 1998). Moreover, $[11 \mathrm{C}]$ cocaine binding to DAT is reduced in human addicts measured by PET (Volkow et al, 1996a), and psychostimulants are less effective at elevating extracellular dopamine levels which corresponds with reduced euphorigenic effects (Volkow et al, 1996b).

We have demonstrated that a prominent preclinical rodent model of cocaine dependence, produced by extended access to cocaine (Ahmed and Koob, 1998), exhibits nearly identical characteristics of striatal dopamine system hypofunction during abstinence as compared with the clinical literature. The extended access model (Ahmed and Koob, 1998), in which animals are allowed daily access to cocaine in $6 \mathrm{~h}$ sessions (or a maximum of 40 injections per session that yields the same effects), results in escalated cocaine intake 
over days (Ferris et al, 2012; Calipari et al, 2014a, b), blunted electrically stimulated dopamine release, blunted cocaineinduced dopamine release measured with voltammetry and microdialysis (Mateo et al, 2005; Ferris et al, 2011, 2012, 2013a; Calipari et al, 2014a), reduced basal extracellular dopamine levels (Mateo et al, 2005; Ferris et al, 2011), mixed results with respect to shifts in dopamine uptake by the DAT depending on the schedule and pattern of intake (Mateo et al, 2005; Ferris et al, 2011, 2012, 2013a; Calipari et al, 2013a), reduced total DAT levels (Calipari et al, 2014b), reduced D2 autoreceptor function (Mateo et al, 2005), and a reduced ability of cocaine and other blockers to inhibit dopamine uptake (Mateo et al, 2005; Ferris et al, 2011, 2012, 2013a; Calipari et al, 2013a, 2014a).

The impetus for the current investigation came from observations that the pharmacological effects of amphetamine on the dopamine system, unlike cocaine and DAT blockers, remained intact and were not disrupted by cocaine self-administration (Ferris et al, 2011, 2012). Given (1) the interest in amphetamine as a pharmacotherapeutic agent to acutely offset a hypodopaminergic state during cocaine abstinence, (2) the fact that cocaine and amphetamine are differentially affected by cocaine self-administration, and (3) the well-documented mechanistic differences between cocaine and amphetamine, a thorough investigation of the lack of cross-tolerance is important. We discovered that the pharmacological effects of amphetamine are not only unaffected by cocaine self-administration (Ferris et al, 2011), but a single administration of amphetamine is capable of fully reversing dopamine system hypofunction caused by an extended history of cocaine self-administration. Most notably, this full reversal remains present even after amphetamine is cleared from the system. Thus, we outline a newly discovered characteristic of amphetamine's effects on dopamine neurochemistry that has profound implications for the regulation of dopamine terminal and DAT function in general, and for amphetamine as a pharmacotherapeutic agent for cocaine addiction.

\section{MATERIALS AND METHODS}

\section{Subjects and General Procedure}

Male, Sprague-Dawley rats (350-375 g; Harlan Laboratories) were used as subjects. All animals were maintained according to the National Institutes of Health guidelines in accredited facilities. The experimental protocol was approved by the Institutional Animal Care and Use Committee at Wake Forest School of Medicine.

Animals were implanted with an intravenous jugular (i.v.) catheter and were single-housed in cages that served as both a home cage and their self-administration chamber. In the initial set of studies, a noncontingent infusion of cocaine $(1.5 \mathrm{mg} / \mathrm{kg}$ in $0.1 \mathrm{ml}$ saline $)$, amphetamine $(0.56 \mathrm{mg} / \mathrm{kg}$ in $0.1 \mathrm{ml}$ saline), or saline $(0.1 \mathrm{ml})$ was infused through the i.v. catheter $24 \mathrm{~h}$ following the start of their final self-administration session. This design yielded five groups: naive rats with saline infusion through i.v. catheters (Naive+Saline), cocaine selfadministration rats with saline infusion (Coc SA+Saline), naive rats with amphetamine infusion (Naive+AMPH), cocaine self-administration rats with amphetamine infusion $(\mathrm{Coc} \mathrm{SA}+\mathrm{AMPH})$, and cocaine self-administration rats with cocaine infusion (Coc SA+Coc). Animals were then killed for voltammetry studies $1 \mathrm{~h}$ after the noncontingent infusion of drug. In a follow-up study, a noncontingent infusion of amphetamine $(0.56 \mathrm{mg} / \mathrm{kg}$ in $0.1 \mathrm{ml}$ saline $)$ was infused through the i.v. catheter exactly as described above, but animals were killed $24 \mathrm{~h}$ after the drug infusion. We selected this dose of amphetamine to be consistent with our earlier studies on amphetamine and cocaine (Ferris et al, 2011) and to match the amount of extracellular dopamine elicited in response to amphetamine to the amount of dopamine elicited by the dose of cocaine used in self-administration. In other words, our goal was to match each drug's ability to elicit similar amounts of dopamine overflow.

\section{Self-Administration Procedures}

The procedures for cocaine self-administration have been described previously (Ferris et al, 2011, 2012) and are repeated herein for clarity. Each animal was maintained on a reverse light cycle ( $0300 \mathrm{~h}$ lights off; $1500 \mathrm{~h}$ lights on), and all self-administration procedures occurred during the active/ dark cycle (0900 to $1500 \mathrm{~h}$ ). Each lever press resulted in the delivery of $1.5 \mathrm{mg} / \mathrm{kg}$ cocaine over $4 \mathrm{~s}$. This dose was chosen because it is the most reinforcing dose, at the top of the dose-response curve in rats responding under a progressiveratio schedule of reinforcement, and preferred over lower doses in choice studies (Richardson and Roberts, 1996). Concurrent with the start of each injection, the lever retracted and a stimulus light located on the lever was activated for $20 \mathrm{~s}$ to signal a time-out period. The session was terminated after 40 injections or after $6 \mathrm{~h}$, whichever occurred first. Once the animals reached the maximum number of injections allowed in a single session (ie, 40), they were required to selfadminister 40 injections per day for five consecutive days before administration of the single, noncontingent drug infusion and subsequent voltammetry studies.

\section{Fast-Scan Cyclic Voltammetry}

All voltammetry experiments were conducted in the morning (active/dark cycle) following the final self-administration session ( $24 \mathrm{~h}$ from the start of the final session). Multiple coronal slices $(400 \mu \mathrm{M})$ containing the nucleus accumbens (NAc) were prepared from each animal with a vibrating tissue slicer while immersed in oxygenated artificial cerebrospinal fluid (aCSF) containing (in mM): $\mathrm{NaCl}$ (126), $\mathrm{KCl}$ (2.5), $\mathrm{NaH}_{2} \mathrm{PO}_{4}$ (1.2), $\mathrm{CaCl}_{2}$ (2.4), $\mathrm{MgCl}_{2}$ (1.2), $\mathrm{NaHCO}_{3}$ (25), glucose (11), L-ascorbic acid (0.4), and $\mathrm{pH}$ adjusted to 7.4. Once sliced, tissue was transferred to the testing chambers containing bath aCSF $\left(32^{\circ} \mathrm{C}\right)$ that flowed at $1 \mathrm{ml} / \mathrm{min}$. After a 30-min equilibration period, a cylindrical carbon fiber microelectrode $(100-200 \mu \mathrm{M}$ length, $7 \mu \mathrm{M}$ radius) and a bipolar stimulating electrode were placed into the core of the NAc. We chose the NAc because it is rich in dopamine nerve terminals and heavily implicated in goal-directed behavior, reinforcement, reward, drug addiction, and important for cocaine self-administration. Note that the effects of cocaine self-administration in our previous work are similar between the NAc core and NAc shell (Mateo et al, 2005). Dopamine was evoked by a single, rectangular, electrical pulse $(300 \mu \mathrm{A}$, $4 \mathrm{~ms}$ ), applied every $5 \mathrm{~min}$. Extracellular dopamine was monitored at the carbon-fiber electrode every $100 \mathrm{~ms}$ by 
applying a triangular voltage waveform $(-0.4$ to +1.2 to $-0.4 \mathrm{~V}$ vs $\mathrm{Ag} / \mathrm{AgCl}, 400 \mathrm{~V} / \mathrm{s})$. Once the extracellular dopamine response was stable, cocaine $(0.3-30 \mu \mathrm{M})$ was applied cumulatively to the brain slice. Immediately following the completion of each concentration-response curve, recording electrodes were calibrated by recording their response (in electrical current; $\mathrm{nA}$ ) to a known concentration of dopamine in aCSF $(3 \mu \mathrm{M})$. All voltammetry data were collected and modeled using Demon Voltammetry and Analysis Software (Yorgason et al, 2011) using MichaelisMenten kinetics. The three voltammetry parameters used in the current investigation were the peak height of the signal (in $\mu \mathrm{M}$ concentration), the maximal rate of dopamine uptake $\left(V_{\max }\right)$, and apparent $\mathrm{K}_{\mathrm{m}}\left(a p p K_{\mathrm{m}}\right)$ to study the effects of release, uptake, and cocaine-induced uptake inhibition, respectively. These parameters are described in detail in previous work (Ferris et al, 2013b), and described briefly here for clarity. $V_{\max }$ is a rate term (measured as [dopamine] per second) that is inversely related to the time it takes dopamine to be cleared when no drug is present, and is measured on the descending slope of the drug-free dopamine curve. App $K_{\mathrm{m}}$ measures the rightward shift/ slowing of the descending limb of the dopamine trace following equilibration of each concentration of cocaine. Data were collected for $15 \mathrm{~s}$ during baseline collections and for $30 \mathrm{~s}$ following administration of cocaine in order to capture the entire descending limb of the curve. Two-way ANOVA with experimental group and concentration of the drug as factors was performed. When significant main effects were obtained $(p<0.05)$, differences between groups at each dose were tested using Bonferroni or Tukey's post hoc tests.

\section{Western Blot Analyses of Fractionated Striatal Samples}

Striatal tissues were processed by centrifugation to separate the cytosolic and the membrane fractions as described previously (Calipari et al, 2014c). Tissue was homogenized in $50 \mathrm{mM}$ Tris $\mathrm{Cl}$ buffer ( $\mathrm{pH} 7.4$ ) containing $150 \mathrm{mM} \mathrm{NaCl}$, $10 \%$ sucrose, and a cocktail of protease inhibitors (SigmaAldrich). A portion of the homogenates was saved, lysed in RIPA buffer, and used as the total homogenate. The remaining homogenates were centrifuged at $20000 \mathrm{~g}$ for $1 \mathrm{~h}$. The supernatant was collected and stored at $-80^{\circ} \mathrm{C}$ for further analyses of the cytosol-associated protein levels. The pellets were collected and resuspended by sonication in $20 \mathrm{mM}$ Tris buffer ( $\mathrm{pH} \mathrm{8,} \mathrm{containing} 1 \mathrm{mM}$ EDTA, $100 \mathrm{mM}$ $\mathrm{NaCl}, 1 \%$ sodium deoxycholate, $1 \mathrm{mM}$ dithiothreitol, and a cocktail of protease and phosphatase inhibitors) and lysed for $1 \mathrm{~h}$ at $4^{\circ} \mathrm{C}$. The lysate was centrifuged at $100000 \mathrm{~g}$ for $60 \mathrm{~min}$ and the supernatants were collected for analyses of membrane-associated protein levels. Protein concentrations were measured using a bicinchoninic acid protein assay kit (Pierce Chemical, Rockford, IL). Samples containing $10 \mu \mathrm{g}$ protein were loaded onto 8\% SDS-polyacrylamide gel. Gels were transferred electrophoretically onto nitrocellulose membranes. After incubation with the blocking buffer containing $5 \%$ nonfat milk in phosphate-buffered saline (PBS), the membranes were probed overnight at $4{ }^{\circ} \mathrm{C}$ with rabbit anti-DAT antibody (Millipore). The membranes were then incubated with goat anti-rabbit secondary antibodies conjugated with peroxidase. Actin was probed with the primary antibody goat anti-actin (Santa Cruz) followed by incubation with donkey anti-goat (Sigma-Aldrich). The enhanced chemiluminescence substrate solution (Pierce Chemical) was applied to the membrane and then exposed to X-ray film. Films were analyzed densitometrically using ImageJ (NIH). The band density was normalized to its respective actin level and then each group normalized to the control group (Naive+Saline). Data were represented relative to the control group.

\section{RESULTS}

Cocaine Self-Administration Reduced Dopamine Release and Uptake and Blunted the Ability of Cocaine to Inhibit Dopamine Uptake

Consistent with a large amount of previous work using this model (Ferris et al, 2012; Calipari et al, 2014a, b), rats increased their rate of responding across all 5 days of cocaine self-administration (day $1=7.25 \pm 0.45$ infusions per $h v s$ day $5=8.76 \pm 0.47$ infusions per $h, p<0.05$ ), indicative of escalation of cocaine intake (mean \pm SEM). Figure 1a (left and middle panels) shows that a 5-day history of cocaine self-administration reduced electrically stimulated dopamine release $\left(t_{(18)}=1.91, p<0.05\right)$. Figure 1a (left and right panels) shows decreased $V_{\max }$ in cocaine self-administration animals $\left(t_{(18)}=2.54, p<0.01\right)$. To ensure that different magnitudes of dopamine release did not influence our measure of $V_{\max }$, we tested whether there was a difference in $V_{\max }$ between the highest and lowest quartiles of dopamine release. There was no difference in $V_{\max }$ based on a quartile split of release $(p>0.05)$, indicating no influence of release on our measure of $V_{\max }$. Furthermore, our $V_{\max }$ data are consistent with membrane DAT expression (see Figure 3), indicating our measure of $V_{\max }$ is a pure measure of uptake and not influenced by release magnitude. Representative pseudocolor plots of cocaine-induced uptake inhibition at $30 \mu \mathrm{M}$ are shown in Figure 1b. Cocaine extends dopamine signaling $(\mathrm{z}$ axis) further out in time by as much as 10 to $15 \mathrm{~s}$ (x axis) in the Naive+Saline group (top panel) relative to Coc SA+Saline group (bottom panel). Grouped data plotted across all concentrations in Figure 1c show that cocaine inhibited dopamine uptake for both groups $\left(\mathrm{F}_{(4,10)}=236.0, p<0.0001\right)$, but this effect was blunted following a 5-day history of cocaine selfadministration (main effect of group: $F_{(1,10)}=19.94$, $p<0.001$, group $\times$ concentration: $\left.F_{(4,40)}=19.69, p<0.0001\right)$. Bonferroni comparisons indicated that the Coc SA+Saline group showed reduced uptake inhibition at the $10 \mu \mathrm{M}$ $(p<0.01)$ and $30 \mu \mathrm{M}(p<0.001)$ concentrations relative to Naive+Saline group.

\section{A Single Amphetamine Infusion Reversed Deficits in Dopamine Terminals Caused by a History of Cocaine Self-Administration}

We performed voltammetry in brain slices $1 \mathrm{~h}$ after a single amphetamine infusion $(0.56 \mathrm{mg} / \mathrm{kg}$, i.v. $)$ in naive and cocaine self-administering animals. Electrically stimulated dopamine release under drug-free bath conditions trended toward decreases following an infusion of amphetamine in both naive and cocaine self-administering animals in a manner that did not appear to deviate from Coc SA+Saline animals 
a

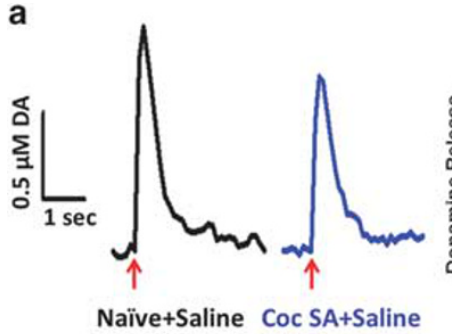

b
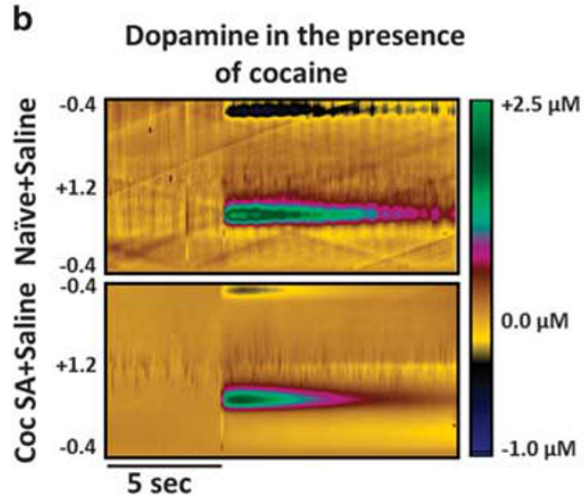
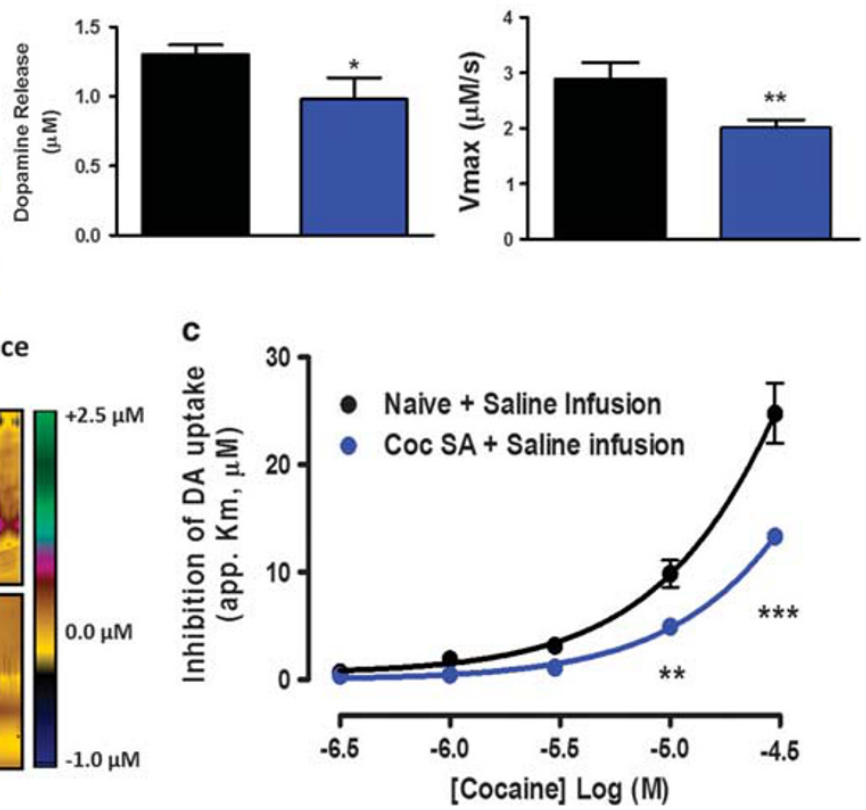

Figure I Cocaine self-administration (Coc SA) produces dopamine system hypofunction in the nucleus accumbens core as measured by voltammetry in brain slices. (a) Coc SA+Saline infusion animals (blue) showed reduced electrically stimulated dopamine release (left and middle panels) and maximal rate of dopamine uptake ( $V_{\max }$ left and right panels) relative to Naive+Saline infusion animals (black). (b) Dopamine ( $\mathrm{z}$ axis), as indicated by its oxidation $+0.6 \mathrm{~V}$ and reduction at $-0.2 \mathrm{~V}$ (y axis), across time ( $x$ axis) is represented as pseudocolor plots. Representative plots demonstrate that the ability of cocaine to inhibit uptake, when applied directly to brain slices, is blunted in Coc SA+Saline animals relative to Naive+Saline animals. (c) Grouped data show a significant reduction in the ability of cocaine to inhibit dopamine uptake following a history of cocaine self-administration. $* * * P<0.00$ I, $* * p<0.0$ I, $* p<0.05$.

(Figure 2a, left panel). There was, however, a main effect of treatment on $V_{\max }\left(\mathrm{F}_{(3,29)}=6.75, p<0.01\right.$; Figure $2 \mathrm{a}$, right panel). Tukey's test indicated that Coc SA+AMPH animals had significantly elevated $V_{\max }$ relative to all three other groups, suggesting an interactive effect between a history of cocaine self-administration and amphetamine infusion. Representative pseudocolor plots of cocaine-induced uptake inhibition at $30 \mu \mathrm{M}$ (Figure $2 \mathrm{~b}$ ) show that the ability of cocaine to extend dopamine signaling ( $\mathrm{z}$ axis) in time ( $\mathrm{x}$ axis), which is blunted in the Coc SA+Saline group (middle panel) relative to Naive+Saline group (top panel), is restored following single amphetamine infusion (bottom panel). Grouped data plotted across all concentrations in Figure $2 \mathrm{c}$ revealed a main effect of treatment $\left(\mathrm{F}_{(3,18)}=8.59\right.$, $p<0.0001)$, a main effect of cocaine concentration $\left(\mathrm{F}_{(4,18)}=\right.$ 139.2, $p<0.001)$ and a treatment $\times$ concentration interaction $\left(\mathrm{F}_{(12,72)}=4.53, p<0.0001\right)$. Bonferroni comparisons indicated a significant decrease in app $K_{\mathrm{m}}$ for Coc SA+Saline relative to Naive+Saline at $10 \mu \mathrm{M}(p<0.01)$ and $30 \mu \mathrm{M}$ $(p<0.001)$ concentrations and an increase in $a p p K_{\mathrm{m}}$ for Coc $\mathrm{SA}+\mathrm{AMPH}$ group relative to all three groups at both 10 and $30 \mu \mathrm{M}$ concentrations. The Naive+AMPH group was not different from the Naive+Saline group.

We also performed voltammetry in brain slices from animals that received a single infusion of cocaine $(1.5 \mathrm{mg} / \mathrm{kg})$ through their i.v. catheters. This group controlled for the possibility of generalized dopamine elevation or any stimulant causing a reversal of cocaine's effects following self-administration. Supplementary Figure 1 shows that a single cocaine infusion did not modulate reductions in dopamine release, uptake, or the sensitivity of cocaine to DAT following a history of cocaine self-administration.
A Single Amphetamine Infusion Reversed Deficits in Membrane-Associated Expression of the Dopamine Transporter Caused by a History of Cocaine Self-Administration

To test whether cocaine self-administration with and without an amphetamine infusion altered $V_{\max }$ via redistribution of the DAT to and from the membrane, we performed western blot analyses on fractionated striatal samples from naive and cocaine self-administering animals with and without amphetamine infusion $1 \mathrm{~h}$ before killing. Data in Figure 3 are consistent with $V_{\max }$ from voltammetry experiments in Figure 2a, right panel. Namely, there was a main effect in both total $\left(\mathrm{F}_{(3,21)}=4.85, p<0.01\right.$; Figure $3 \mathrm{a}$ and $\left.\mathrm{b}\right)$ and membrane $\left(\mathrm{F}_{(3,21)}=5.35, p<0.001\right.$; Figure $3 \mathrm{a}$ and $\left.\mathrm{d}\right)$ DAT levels, but the trend toward increased cytosolic DAT levels in Coc SA + Saline and Naive+AMPH groups yielded no main effects (Figure $3 \mathrm{a}$ and $\mathrm{c}$ ). Cocaine self-administration reduced total DAT levels, and a single amphetamine infusion restored DAT levels equivalent to those observed in Naive+Salinetreated animals (Figure $3 \mathrm{~b}$ ). The effect on the total DAT level (Figure $3 \mathrm{~b}$ ) appeared to be attributable to the significant reductions in membrane DAT levels following cocaine selfadministration and the amphetamine-induced restoration of membrane DAT levels in cocaine self-administration animals (Figure 3d).

\section{Rescue of Dopamine Terminal Function Following Amphetamine Infusion Was Stable}

We next tested whether restoration of dopamine terminal function by amphetamine remained $24 \mathrm{~h}$ following 
a

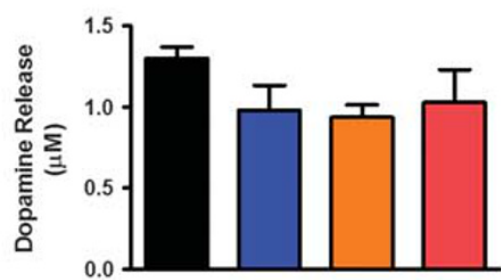

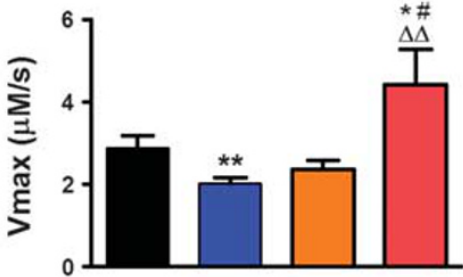

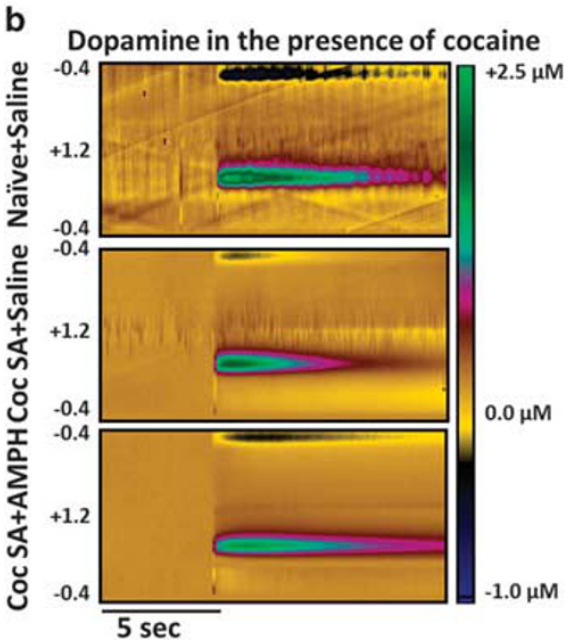

C

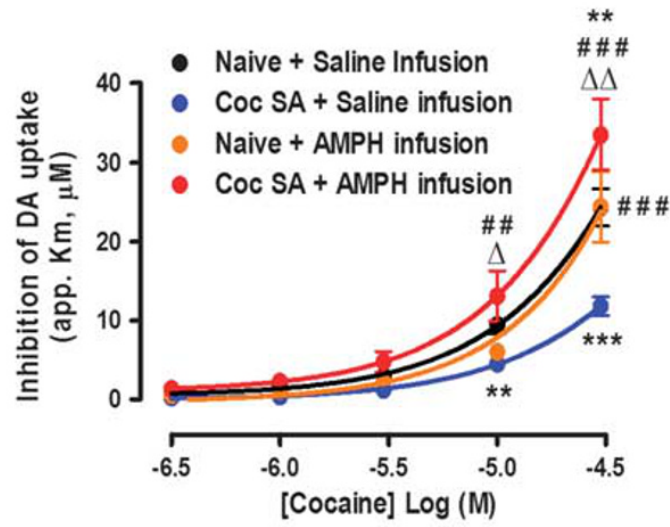

Figure 2 A single infusion of amphetamine $(A M P H)$ decreases the maximal rate of dopamine uptake $\left(V_{\max }\right)$ with no effect on cocaine potency in naive animals, but increases $V_{\max }$ and restores the ability of cocaine to inhibit dopamine uptake in cocaine self-administration (Coc SA) animals within I h. (a) AMPH infusion in naive animals (orange) produced a trend toward decreased dopamine release (left panel) and decreased $V_{\max }$ (right panel), similar to levels observed following Coc SA (blue). AMPH after I h does not influence release in Coc SA animals (red), but does significantly increase $V_{\text {max }}$ above Naive + Saline-treated animals (black). (b) Dopamine ( $\mathrm{z}$ axis), as indicated by its oxidation $+0.6 \mathrm{~V}$ and reduction at $-0.2 \mathrm{~V}$ ( $y$ axis), across time ( $x$ axis) is represented as pseudocolor plots. Representative plots demonstrate that the ability of cocaine to inhibit uptake, when applied directly to brain slices, is blunted in Coc +Saline animals (middle panel) relative to Naive+Saline animals (top panel), and fully restored I h after AMPH infusion (bottom panel). (c) AMPH (red) reverses the reduced ability of cocaine to inhibit dopamine uptake after cocaine self-administration, with no effect in Naive animals (orange). $* * * P<0.001$, *** $p<0.0$ I, ${ }^{*} p<0.05$ vs Naive+Saline; ${ }^{\# \#} p<0.00$ I, ${ }^{\# \#} p<0.0$ I vs Coc SA+Saline; ${ }^{\Delta} p<0.0$ I, ${ }_{p} p<0.05$ vs Naive+AMPH.

a

1. Naïve+Saline infusion

2. Coc $S A+$ Saline infusion

3. Coc SA+AMPH infusion

4. Naïve+AMPH infusion

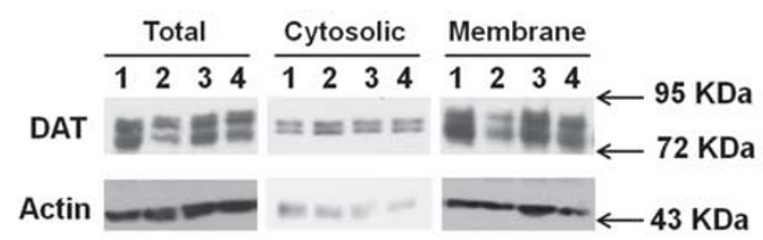

b

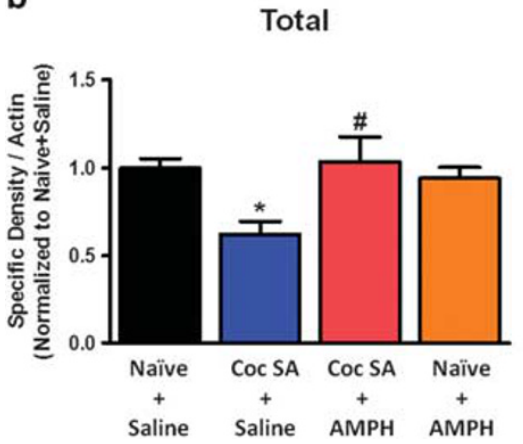

c

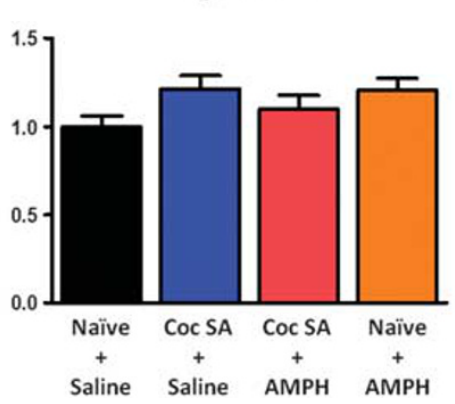

d

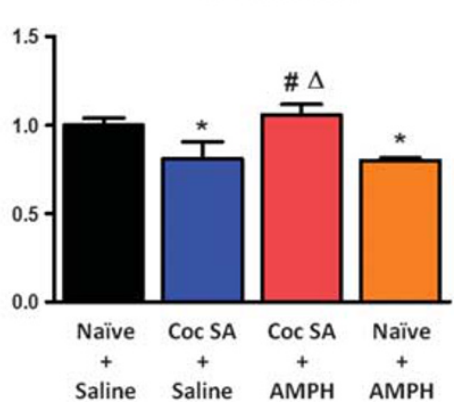

Figure 3 Amphetamine $(\mathrm{AMPH})$ reverses the decrease in membrane-associated expression of the dopamine transporter that follows cocaine selfadministration (Coc SA) as measured by western blot analysis. (a) Representative blots of all four treatment groups. (b) Total DAT expression shows significant decreases following Coc SA that is reversed by an AMPH infusion. (c) No significant shift in cytosolic DAT levels across all four groups. (d) Membrane-associated DAT localization shows significant decreases following Coc SA that is reversed by an AMPH infusion, in addition to decreases in naive animals following AMPH infusion. ${ }^{*} P<0.05$ vs Naive+Saline; ${ }^{\#} p<0.05$ vs Coc SA+Saline; ${ }_{p} p<0.05$ vs Naive+AMPH. 
a
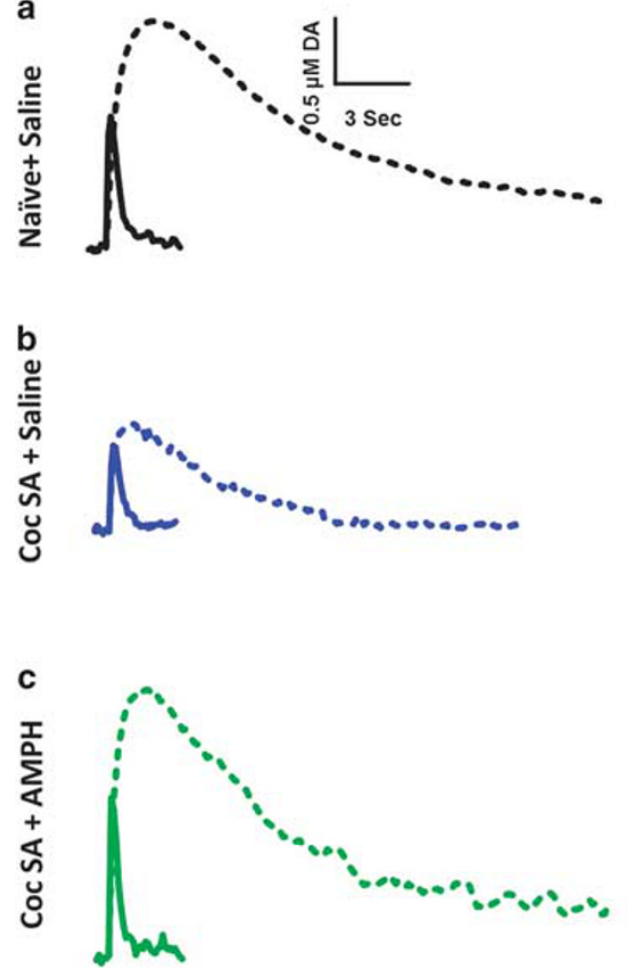

d

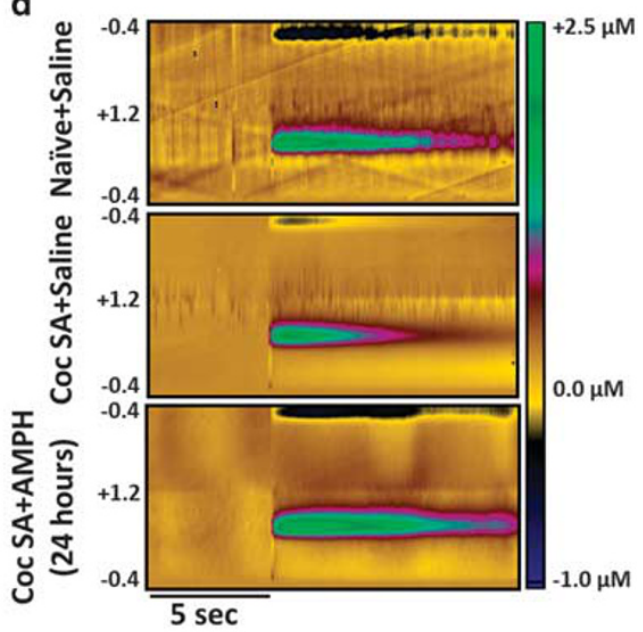

e

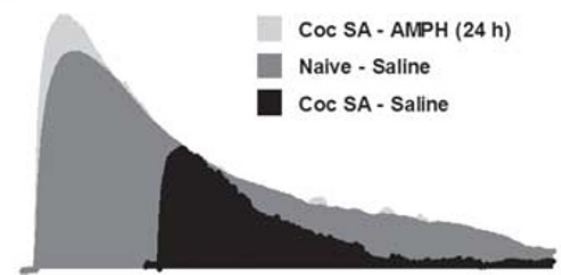

Figure 4 Representative dopamine traces demonstrate reduced dopamine function across multiple indices (release, uptake, and cocaine inhibition of uptake) following cocaine self-administration (Coc SA) that is fully restored $24 \mathrm{~h}$ following a single amphetamine (AMPH) infusion. Dopamine release and uptake under drug-free conditions (solid lines in a-c) and following bath application of $30 \mu \mathrm{M}$ cocaine (dashed lines in a-c) in Naive+Saline (a, black), Coc SA +Saline (b, blue), and Coc SA+AMPH after $24 \mathrm{~h}$ (c, green). (d) Dopamine (z axis), as indicated by its oxidation $+0.6 \mathrm{~V}$ and reduction at $-0.2 \mathrm{~V}$ (y axis), across time ( $x$ axis) is represented as pseudocolor plots. Representative plots demonstrate that the ability of cocaine to inhibit uptake, when applied directly to brain slices, is blunted in Coc SA+Saline animals (middle panel) relative to Naive+Saline animals (top panel), and fully restored $24 \mathrm{~h}$ after AMPH infusion (bottom panel). (e) To better represent blunted cocaine effects at the dopamine transporter, the representative dopamine trace for the Coc SA+Saline group is shifted later in time to match the peak height dopamine concentration of the Naive+Saline and Coc SA+AMPH groups (black vs gray and light gray).

amphetamine administration. Figures $4 a-c$ show representative dopamine traces under drug-free conditions (solid traces) and following bath application of $30 \mu \mathrm{M}$ cocaine (dashed traces) for Naive+Saline (black traces, top), Coc SA+Saline (blue traces, middle), and Coc SA+AMPH after $24 \mathrm{~h}$ (green traces, bottom). The ability of cocaine to facilitate dopamine overflow was substantially reduced in animals with a history of cocaine self-administration (blue $v s$ black traces), whereas a single amphetamine infusion was able to fully restore dopamine signaling elicited under conditions in which aCSF was drug free and when it contained cocaine (green $v$ s black traces). Figure $4 \mathrm{~d}$ and e (area under the curve following cocaine application) shows that both decreased peak height and decreased rightward shift on the descending limb of the curve accounted for the reduced ability of cocaine to increase dopamine following cocaine self-administration. These parameters were restored $24 \mathrm{~h}$ after a single amphetamine infusion. In particular, the reduced ability of cocaine to inhibit dopamine uptake after cocaine self-administration and the full reversal after amphetamine infusion is exemplified in Figure 4e. Even when the curve for Coc SA+Saline is shifted so that the peak height matches the dopamine concentration of the Naive+Saline group (Figure 4e), the descending curve reaches baseline many seconds before naive animals.

There was no main effect of treatment group on dopamine release, with a trend toward restored dopamine release $24 \mathrm{~h}$ after amphetamine infusion in cocaine self-administering animals (Figure 5a). There was a main effect of treatment group on $V_{\max }\left(\mathrm{F}_{(3,35)}=9.58, p<0.0001\right.$; Figure $\left.5 \mathrm{~b}\right)$, with Tukey's analyses indicating significantly faster $V_{\max }$ in the group tested $24 \mathrm{~h}$ after amphetamine infusion relative to Coc $\mathrm{SA}+$ Saline animals but not Naive+Saline animals. Cocaineinduced uptake inhibition in Figure $5 \mathrm{c}$ shows a main effect of treatment $\left(\mathrm{F}_{(3,20)}=11.60, p<0.0001\right)$, main effect of cocaine concentration $\left(\mathrm{F}_{(4,20)}=262.5, p<0.0001\right)$, and a treatment $\times$ concentration interaction $\left(\mathrm{F}_{(12,80)}=7.85, p<0.0001\right)$. Bonferroni analysis indicates that amphetamine infusion $24 \mathrm{~h}$ before voltammetry testing fully restored cocaine-induced uptake inhibition to naive levels. Cocaine-induced increases in peak height of the signal in Figure $5 \mathrm{~d}$ shows a main effect of treatment $\left(\mathrm{F}_{(3,20)}=5.30, p<0.01\right)$, main effect of concentration, $\left(\mathrm{F}_{(4,20)}=58.43, p<0.0001\right)$, and a treatment $\times$ concentration interaction $\left(\mathrm{F}_{(12,80)}=2.08, p<0.05\right)$. Thus, amphetamine infusion $24 \mathrm{~h}$ before voltammetry testing fully restored cocaine-induced facilitation of release to naive levels.

\section{DISCUSSION}

In the current investigation and in work over the course of 10 years, we have established that multiple models that demonstrate increases in specific behavioral characteristics 
a

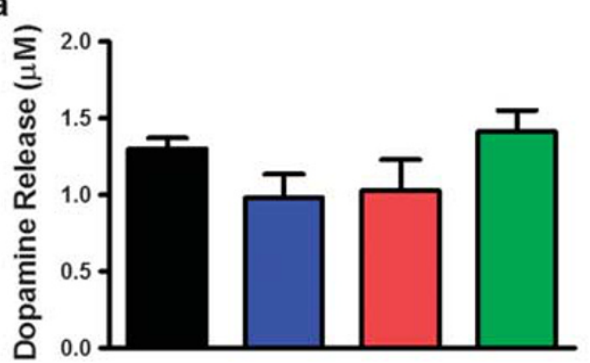

C

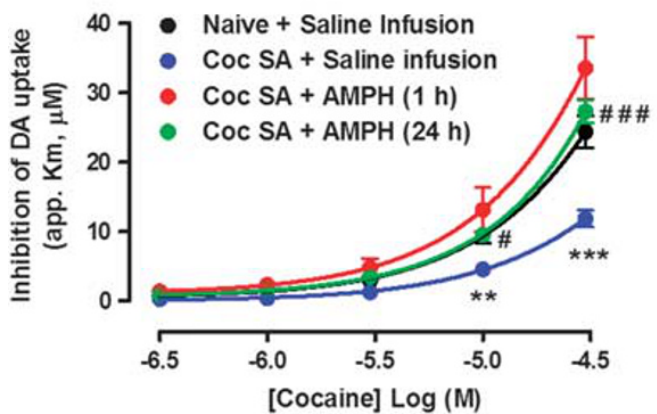

b

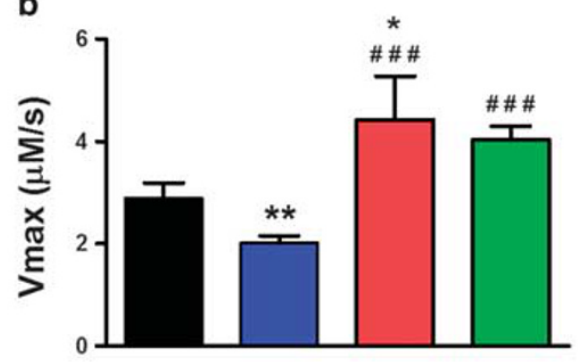

d

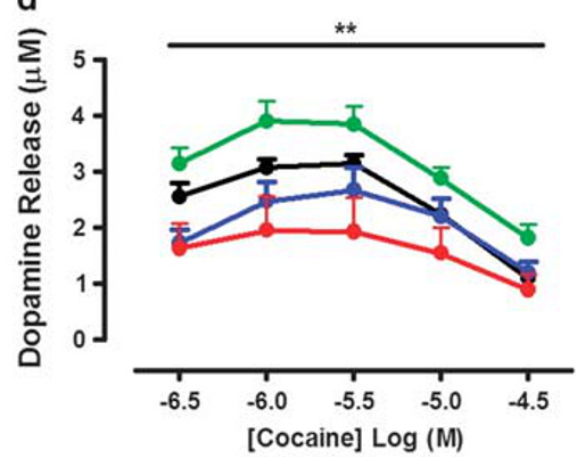

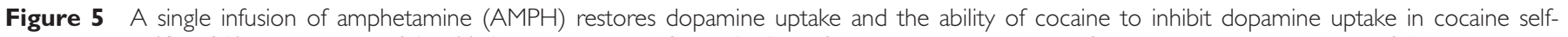

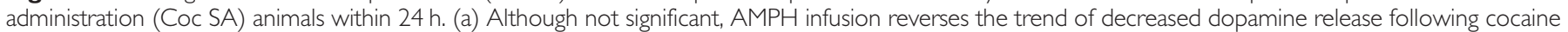

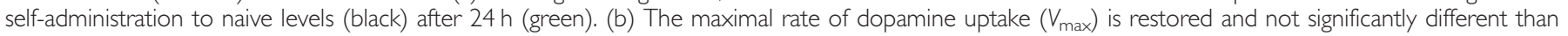

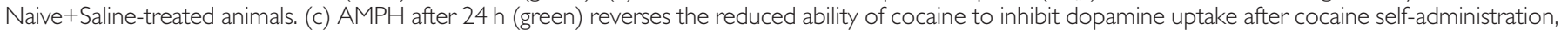

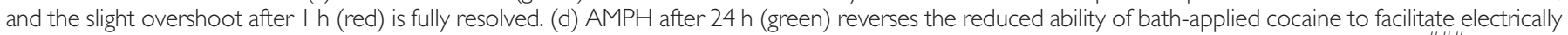

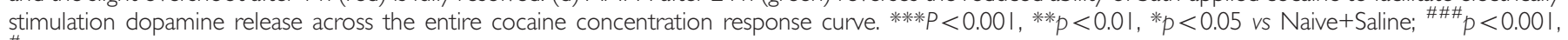
${ }^{\#} p<0.05$ Coc SA+AMPH(24 h) vs Coc SA+Saline.

and responses for cocaine, such as escalation of cocaine intake/ motivation on fixed and progressive ratios, result in a hypodopaminergic resting state of dopamine terminal function in addition to a reduced ability of cocaine to inhibit dopamine uptake and correspondingly increase dopamine in the extracellular space (Ferris et al, 2012; Calipari et al, 2014b; however, see Ahmed et al, 2003). Phillips and colleagues (Willuhn et al, 2014) have mechanistically linked dopamine system deficits with escalation of cocaine intake and showed that restoration of phasic dopamine release eliminated escalated intake of cocaine. This body of work strongly suggests that 'sensitization' of mesolimbic dopamine in response to cocaine is not a prerequisite for escalation of intake or escalation in the amount of work an animal will put forth to receive drug, and instead reduced dopamine function may be related to tolerance to the ratedecreasing effects of cocaine thought to be associated with escalation of cocaine intake (Zernig et al, 2007). Furthermore, this work is consistent with work indicating that D1 or D2 receptor blockade in the NAc core facilitates escalation of cocaine intake (Suto et al, 2009) whereas combined infusion of D1/D2 agonists into the NAc core promotes satiety in animals that are self-administering cocaine, effectively blocking escalation (Suto and Wise, 2011). Indeed, animals' titration of responses across shifting cocaine doses or during self-stimulation in order to meet satiety thresholds is a well-documented characteristic of cocaine self-administration (see, eg, Zimmer et al, 2011, 2013; Norman et al, 2014).

Here, we describe the rescue of deficits in dopamine function by a single infusion of amphetamine. Specifically, a single i.v. infusion of amphetamine rapidly reversed cocaine self-administration-induced decreases in membrane and total DAT expression, $V_{\max }$, and the ability of cocaine to inhibit dopamine uptake within $1 \mathrm{~h}$. This restoration of DAT function persisted for at least $24 \mathrm{~h}$ after amphetamine infusion, and was followed at the 24-h time point by a rescue of dopamine release elicited by electrical stimulation. We have previously published that restoration of dopamine nerve-terminal function and the ability of cocaine to inhibit dopamine uptake does not occur until 14 days following cessation of cocaine self-administration in animals that do not receive an amphetamine infusion (Ferris et al, 2011). This demonstrates that the amphetamine-induced reversal of dopamine deficits at the 1 and $24 \mathrm{~h}$ time points is not simply due to withdrawal from cocaine self-administration.

One surprising observation was a differential effect of amphetamine on the presynaptic dopamine terminal in animals with a history of cocaine self-administration as compared with cocaine-naive controls. Cocaine self-administration decreased DAT membrane expression and $V_{\max }$, and these decreases were completely restored (ie, increased) to control levels $1 \mathrm{~h}$ following a single amphetamine infusion. However, in naive animals, a single amphetamine infusion decreased DAT membrane expression and $V_{\max }$, demonstrating that amphetamine effects on these endpoints are substantially modulated by previous experience with cocaine. Although membrane expression of the DAT as measured by western blotting in the current investigation is not necessarily indicative of DAT cell-surface expression per se, a reduction in membrane expression following amphetamine infusion in naive animals is consistent with a large body of 
literature on amphetamine-induced DAT internalization (Fleckenstein et al, 1997, 1999; Saunders et al, 2000; Boudanova et al, 2008; Richards and Zahniser, 2009; Hong and Amara, 2013). Indeed, previous studies have reported substrate-induced downregulation of surface DAT expression anywhere from $1 \mathrm{~min}$ to hours after administration in cultured cell models or in synaptosomes (Fleckenstein et al, 1999; Saunders et al, 2000; Richards and Zahniser, 2009).

A mechanism for this differential effect of amphetamine on expression and function based on a history of cocaine is unclear. Although cocaine and amphetamine binding sites largely overlap at the DAT (Beuming et al, 2008), they may activate different second messenger signals. A history of cocaine experience may modulate amphetamine's signaling cascade before amphetamine ever being administered, leading to the marked increase in membrane-associated DAT levels and DAT function observed in the present studies. As a precautionary note, it should be pointed out that the effect of cocaine self-administration history on DAT expression remains equivocal with examples of increased, decreased, and no change in DAT expression in all species investigated (Narendran and Martinez, 2008). For example, our observation of decreased DAT expression and $V_{\max }$ following cocaine self-administration, despite being replicated numerous times in our model, differs to some degree from the majority of human studies (Narendran and Martinez, 2008; Little et al, 1993; Malison et al, 1998), and even some rat (Oleson et al, 2009; Calipari et al, 2013a) and nonhuman primate work (Letchworth et al, 2001). These examples show either increases or no change in DAT expression following a history of cocaine self-administration. There is typically at least one discrepancy (if not numerous discrepancies) between research that shows decreased DAT expression and $V_{\max }$ compared with others that show increased DAT expression and $V_{\max }$. Perhaps any one discrepancy alone is sufficient to mediate the differential effects on DAT expression and/or $V_{\max }$. One difference includes the degree of abstinence from cocaine. Indeed, we previously observed an increase in $V_{\max }$ following extended withdrawal in rats that perhaps better resembles the human data (Ferris et al, 2011). Another difference includes pattern of cocaine intake. We previously observed increases in $V_{\max }$ following intermittent access self-administration despite having almost no period of abstinence (Calipari et al, 2013a). Intermittent patterns of intake may more closely resemble human patterns of intake as it is unlikely humans selfadminister high levels of cocaine continuously for $6 \mathrm{~h}$ per day over the course of 1 week. Even if humans binge in a pattern similar to our model, it is possible that there are periods of abstinence followed by additional binging patterns over the period of several years. Therefore, understanding the effects of amphetamine following cocaine self-administration on DAT expression is not fully possible without more work to test the effects of amphetamine infusion under different selfadministration conditions, including protracted withdrawal from cocaine, alternative access paradigms, and following different doses of cocaine.

In addition to shifts in DAT membrane expression and $V_{\max }$ following cocaine self-administration, we also observed decreases in the ability of cocaine to inhibit dopamine uptake. We have speculated that a cocaine-induced conformational change of surface DATs, rather than a shift in
DAT surface level, is responsible for reduced cocaine effects (Ferris et al, 2011). This is similar to how specific DAT mutations can reduce cocaine potency in mice while sparing substrate potency (Chen et al, 2006; Tilley et al, 2009). Reduced cocaine binding with no change in DAT density has been demonstrated in humans (Volkow et al, 1996a, b). Our reasoning for ruling out trafficking for reduced cocaine potency stems from the fact that $V_{\max }$ is tightly linked to DAT levels in this study and in others (Calipari et al, 2013b), and we have shown that $V_{\max }$ is not mechanistically linked to cocaine-induced decreases in cocaine potency (Mateo et al, 2005; Ferris et al, 2012; Calipari et al, 2013b). Nevertheless, there is a distinct possibility that amphetamine causes an insertion of DATs at the membrane that have had no prior direct exposure to cocaine, and therefore would not be modified. These newly inserted DATs might be equally sensitive to cocaine as DATs from naive animals, thus reversing the reduced cocaine effects at the DAT. This hypothesis is consistent with recent reports showing that inducible expression of wild-type DATs can reestablish cocaine potency in mice that initially only express cocaineinsensitive DATs (O’Neill et al, 2014). Further investigation is needed to test this hypothesis particularly since there was no significant fluctuation in cytosolic DAT expression across our groups. This suggests that redistribution between the membrane and cytosol may not be responsible for shifts in DAT levels and $V_{\max }$ and that amphetamine-induced introduction of 'new' DATs may not be at play. On the contrary, a shift in membrane DAT expression with no shift in cytosolic DAT expression supports a different hypothesis than what we have suggested in previous work. Specifically, we have hypothesized that a history of cocaine selfadministration could be promoting the formation of DAT oligomers or higher-order DAT complexes with other proteins (Ferris et al, 2012). The functional effects of DAT oligomerization have yet to be fully elucidated, but early work hypothesizes that formation of DAT oligomers could lead to many of the same functional outcomes found in the current work. For example, oligomer formation may reduce monomers, reduce DAT function, and reduce the affinity of certain ligands (Chen and Reith, 2007; Sitte et al, 2004). This is consistent with our observation of reduced membrane monomer DAT expression, $V_{\max }$, and reduced ability of cocaine to inhibit dopamine uptake. Moreover, amphetamine has been shown to dissociate DAT oligomers in cell culture studies (Chen and Reith, 2008). Therefore, a single amphetamine infusion may be reestablishing DAT monomer expression, increasing $V_{\max }$, and restoring the ability of cocaine to inhibit dopamine uptake via dissociating DAT oligomers or higher-order complexes that were formed by cocaine self-administration.

In addition to the effects of amphetamine after $1 \mathrm{~h}$, we also show that cocaine-induced reductions in $V_{\max }$ and cocaine potency remained reversed $24 \mathrm{~h}$ after amphetamine infusion, and that an additional restoration of dopamine release manifested only at this later time point. Thus, this time point not only confirmed that these effects are likely not transient, but showed that amphetamine can reverse deficits in dopamine release caused by cocaine self-administration, although in a delayed manner relative to reversal of other nerve-terminal functions. The delayed restoration of release suggests that the amphetamine-induced reexpression of DAT 
monomers on the membrane may be necessary for, and lead to, increases in the amount of releasable dopamine. For example, it was recently discovered that DAT expression can determine, at least in part, the amount of readily releasable dopamine (Egana et al, 2009; Ferris et al, 2014). However, if DAT expression leads to refilling of vesicles, it is clear that some amount of time longer than $1 \mathrm{~h}$, but less than $24 \mathrm{~h}$, is required for this process.

The inverse relationship between mesolimbic dopamine function and cocaine intake demonstrated here is important, because the putative mechanism for amphetamine as an agonist therapy has its foundation in decreasing cocaine intake by increasing extracellular dopamine tone during the cocaine selfadministration session (Rothman et al, 2006, 2008). Continuous amphetamine administration delivered during cocaine selfadministration sessions is effective at reducing breakpoints on a progressive-ratio schedule (Negus and Mello, 2003a; Chiodo et al, 2008; Czoty et al, 2010; Zimmer et al, 2014), reducing second-order responding for cocaine (Negus and Mello, 2003b), and reducing preference for cocaine in a choice paradigm (Negus, 2003) in both rats and/or nonhuman primates. Similarly, oral d-amphetamine treatment has been shown to reduce cocaine use in human addicts (Grabowski et al, 2001, 2004a, b). We show here, for the first time, that a single amphetamine infusion also reverses cocaine-induced deficits in dopaminergic terminals. A reversal of cocaine's effects after direct pharmacological effects of amphetamine have dissipated is consistent with behavioral studies showing reduced progressive ratio responding following discontinuation of amphetamine treatment that can last for days (Chiodo et al, 2008; Czoty et al, 2010), and even weeks in some animals (Czoty et al, 2011), well after the acute pharmacological effects of amphetamine have passed. It is unclear, however, whether the effects of cocaine are reestablished following administration of cocaine that occurs after amphetamine treatment, and this will be an important determinant of the therapeutic potential of amphetamine to reverse cocaine-induced adaptations to dopamine systems. Moreover, additional studies are underway to investigate whether the reversal of cocaine's effects is a pharmacotherapeutic characteristic that can be generalized to other releasers as well-perhaps one with less inherent risk of abuse than amphetamine. In addition, it is presently unclear whether the dose of amphetamine infusion dictates this reversal, and whether the effects we see here underlie the efficacy of amphetamine at reducing cocaine selfadministration behavior. If such is the case, then not only does this research document a novel characteristic of amphetamine function, but it also expands amphetamine's pharmacotherapeutic mechanisms from a simple replacement therapy to a multifaceted therapy that includes reversal of cocaine-induced plasticity of dopamine function.

\section{FUNDING AND DISCLOSURE}

The authors declare no conflict of interest.

\section{ACKNOWLEDGMENTS}

This work was funded by NIH grants R01 DA021325, R01 DA030161, R01 DA014030 (to SRJ), K99 DA031791 (to MJF), T32 DA007246 (to MJF and ESC), F31 DA031533 (to ESC),
F31 DA037710, T32 AA007565 (to CAS), and F31 DA035558 (to JHR).

\section{REFERENCES}

Ahmed SH, Koob GF (1998). Transition from moderate to excessive drug intake: change in hedonic set point. Science 282: 298-300.

Ahmed SH, Lin D, Koob GF, Parsons LH (2003). Escalation of cocaine self-administration does not depend on altered cocaineinduced nucleus accumbens dopamine levels. J Neurochem 86: 102-113.

Beuming T, Kniazeff J, Bergmann ML, Shi L, Gracia L, Raniszewska K et al (2008). The binding sites for cocaine and dopamine in the dopamine transporter overlap. Nat Neurosci 11: 780-789.

Boudanova E, Navaroli DA, Melikian HE (2008). Amphetamineinduced decreases in dopamine transporter surface expression are protein kinase C-independent. Neuropharmacology 54: 605-612.

Calipari ES, Ferris MJ, Zimmer BA, Roberts DCS, Jones SR (2013a). Temporal pattern of cocaine intake determines tolerance vs sensitization of cocaine effects at the dopamine transporter. Neuropsychopharmacology 38: 2385-2392.

Calipari ES, Ferris MJ, Salahpour A, Caron MG, Jones SR (2013b). Methylphenidate amplifies the potency and reinforcing effects of amphetamines by increasing dopamine transporter expression. Nat Commun 4: 2720.

Calipari ES, Ferris MJ, Jones SR (2014a). Extended access of cocaine self-administration results in tolerance to the dopamine-elevating and locomotor-stimulating effects of cocaine. J Neurochem 128: 224-232.

Calipari ES, Ferris MJ, Melchior JR, Bermejo K, Salahpour A, Roberts DCS et al (2014b). Methylphenidate and cocaine selfadministration produce distinct dopamine terminal alterations. Addict Biol 19: 145-155.

Calipari ES, Sun HG, Eldeeb K, Luessen DJ, Feng X, Howlett AC et al (2014c). Amphetamine self-administration attenuates dopamine D2 autoreceptor function. Neuropsychopharmacology 39: $1833-1842$.

Chen NH, Reith MEA (2007). Substrates and inhibitors display different sensitivity to expression level of the dopamine transporter in heterologously expressing cells. J Neurochem 101: 377-388.

Chen NH, Reith MEA (2008). Substrates dissociate dopamine transporter oligomers. J Neurochem 105: 910-920.

Chen R, Tilley MR, Wei H, Zhou FW, Zhou FM, Ching S et al (2006). Abolished cocaine reward in mice with a cocaineinsensitive dopamine transporter. Proc Natl Acad Sci USA 103: 9333-9338.

Chiodo KA, Lack CM, Roberts DCS (2008). Cocaine selfadministration reinforced on a progressive ratio schedule decreases with continuous $\mathrm{D}$-amphetamine treatment in rats. Psychopharmacology 200: 465-473.

Czoty PW, Martelle JL, Nader MA (2010). Effects of chronic d-amphetamine administration on the reinforcing strength of cocaine in rhesus monkeys. Psychopharmacology 209: 375-382.

Czoty PW, Gould RW, Martelle JL, Nader MA (2011). Prolonged attenuation of the reinforcing strength of cocaine by chronic d-amphetamine in rhesus monkeys. Neuropsychopharmacology 36: $539-547$.

Egana LA, Cuevas RA, Baust TB, Parra LA, Leak RK, Hochendoner S et al (2009). Physical and functional interaction between the dopamine transporter and the synaptic vesicle protein synaptogyrin-3. J Neurosci 29: 4592-4604.

Ferris MJ, Mateo Y, Roberts DCS, Jones SR (2011). Cocaineinsensitive dopamine transporters with intact substrate transport produced by self-administration. Biol Psychiatry 69: 201-207.

Ferris MJ, Calipari ES, Mateo Y, Melchior JR, Roberts DCS, Jones SR (2012). Cocaine self-administration produces pharmacodynamic 
tolerance: differential effects on the potency of dopamine transporter blockers, releasers, and methylphenidate. Neuropsychopharmacology 37: 1708-1716.

Ferris MJ, Calipari ES, Melchior JR, Roberts DCS, Espana RA, Jones SR (2013a). Paradoxical tolerance to cocaine after initial supersensitivity in drug-use-prone animals. Eur J Neurosci 38: 2628-2636.

Ferris MJ, Calipari ES, Yorgason JT, Jones SR (2013b). Examining the complex regulation and drug-induced plasticity of dopamine release and uptake using voltammetry in brain slices. ACS Chem Neurosci 4: 693-703.

Ferris MJ, Espana RA, Locke JL, Konstantopoulos JK, Rose JH, Chen $\mathrm{R}$ et al (2014). Dopamine transporters govern diurnal variation in extracellular dopamine tone. Proc Natl Acad Sci USA 111: E2751-E2759.

Fleckenstein AE, Metzger RR, Wilkins DG, Gibb JW, Hanson GR (1997). Rapid and reversible effects of methamphetamine on dopamine transporters. J Pharmacol Exp Ther 282: 834-838.

Fleckenstein AE, Haughey HM, Metzger RR, Kokoshka JM, Riddle EL, Hanson JE et al (1999). Differential effects of psychostimulants and related agents on dopaminergic and serotonergic transporter function. Eur J Pharmacol 382: 45-49.

Grabowski J, Rhoades H, Schmitz J, Stotts A, Daruzska LA, Creson D et al (2001). Dextroamphetamine for cocainedependence treatment: a double-blind randomized clinical trial. J Clin Psychopharmacol 21: 522-526.

Grabowski J, Shearer J, Merrill J, Negus SS (2004a). Agonist-like, replacement pharmacotherapy for stimulant abuse and dependence. Addict Behav 29: 1439-1464.

Grabowski J, Rhoades H, Stotts A, Cowan K, Kopecky C, Dougherty A et al (2004b). Agonist-like or antagonist-like treatment for cocaine dependence with methadone for heroin dependence: two doubleblind randomized clinical trials. Neuropsychopharmacology 29: 969-981.

Hong WMC, Amara SG (2013). Differential targeting of the dopamine transporter to recycling or degradative pathways during amphetamine- or PKC-regulated endocytosis in dopamine neurons. FASEB J 27: 2995-3007.

Letchworth SR, Nader MA, Smith HR, Friedman DP, Porrino LJ (2001). Progression of changes in dopamine transporter binding site density as a result of cocaine self-administration in rhesus monkeys. J Neurosci 21: 2799-2807.

Little KY, Kirkman JA, Carroll FI, Clark TB, Duncan GE (1993). Cocaine use increases [H-3] Win-35428 binding-sites in human striatum. Brain Res 628: 17-25.

Malison RT, Best SE, van Dyck CH, McCance EF, Wallace EA, Laruelle $\mathrm{M}$ et al (1998). Elevated striatal dopamine transporters during acute cocaine abstinence as measured by [I-123]betaCIT SPECT. Am J Psychiatry 155: 832-834.

Malison RT, Mechanic KY, Klummp H, Baldwin RM, Kosten TR, Seibyl JP et al (1999). Reduced amphetamine-stimulated dopamine release in cocaine addicts as measured by [I-123] IBZM SPECT. J Nucl Med 40: 110P.

Martinez D, Narendran R, Foltin RW, Slifstein M, Hwang DR, Broft A et al (2007). Amphetamine-induced dopamine release: markedly blunted in cocaine dependence and predictive of the choice to selfadminister cocaine. Am J Psychiatry 164: 622-629.

Mateo Y, Lack CM, Morgan D, Roberts DCS, Jones SR (2005). Reduced dopamine terminal function and insensitivity to cocaine following cocaine binge self-administration and deprivation. Neuropsychopharmacology 30: 1455-1463.

Narendran R, Martinez D (2008). Cocaine abuse and sensitization of striatal dopamine transmission: A critical review of the preclinical and clinical imaging literature. Synapse 62: 851-869.

Negus SS, Mello NK (2003a). Effects of chronic d-amphetamine treatment on cocaine- and food-maintained responding under a progressive-ratio schedule in rhesus monkeys. Psychopharmacology 167: 324-332.
Negus SS, Mello NK (2003b). Effects of chronic d-amphetamine treatment on cocaine- and food-maintained responding under a second-order schedule in rhesus. Drug Alcohol Dependence 70: $39-52$.

Negus SS (2003). Rapid assessment of choice between cocaine and food in rhesus monkeys: Effects of environmental manipulations and treatment with d-amphetamine and flupenthixol. Neuropsychopharmacology 28: 919-931.

Norman AB, Tabet MR, Norman MK, Tsibulksy VL (2014). Maintained cocaine self-administration is determined by quantal responses: implications for the measurement of antagonist potency. J Pharmacol Exp Ther 348: 311-315.

Oleson EB, Talluri S, Childers SR, Smith JE, Roberts DCS, Bonin KD et al (2009). Dopamine uptake changes associated with cocaine self-administration. Neuropsychopharmacology 34: 1174-1184.

O'Neill B, Tilley MR, Han DD, Thirtamara-Rajamani K, Hill ER, Bishop GA et al (2014). Behavior of knock-in mice with a cocaine-insensitive dopamine transporter after virogenetic restoration of cocaine sensitivity in the striatum. Neuropharmacology 79: 626-633.

Richards TL, Zahniser NR (2009). Rapid substrate-induced downregulation in function and surface localization of dopamine transporters: rat dorsal striatum versus nucleus accumbens. J Neurochem 108: 1575-1584.

Richardson NR, Roberts DCS (1996). Progressive ratio schedules in drug self-administration studies in rats: a method to evaluate reinforcing efficacy. J Neurosci Methods 66: 1-11.

Rothman RB, Blough BE, Baumann MH (2006). Dual dopamine-5HT releasers: potential treatment agents for cocaine addiction. Trends Pharmacol Sci 27: 612-618.

Rothman RB, Blough BE, Baumann MH (2008). Dopamine/ serotonin releasers as medications for stimulant addictions. Prog Brain Res 172: 385-406.

Rush CR, Stoops WW (2012). Agonist replacement therapy for cocaine dependence: a translational review. Future Med Chem 4: 245-265.

Saunders C, Ferrer JV, Shi L, Chen JY, Merrill G, Lamb ME et al (2000). Amphetamine-induced loss of human dopamine transporter activity: an internalization-dependent and cocainesensitive mechanism. Proc Natl Acad Sci USA 97: 6850-6855.

Sitte HH, Farhan H, Javitch JA (2004). Oligomerization as a determinant of transporter function and trafficking. Mol Interv 4: $38-47$.

Substance Abuse and Mental Health Services Administration (SAMHSA) (2008). National Survey on Drug Use and Health Available at http://oas.samhsa.gov/nhsda.htm.

Suto N, Ecke LE, Wise RA (2009). Control of within-binge cocaineseeking by dopamine and glutamate in the core of nucleus accumbens. Psychopharmacology 205: 431-439.

Suto N, Wise RA (2011). Satiating Effects of Cocaine Are Controlled by Dopamine Actions in the Nucleus Accumbens Core. J Neurosci 31: 17917-17922.

Tilley MR, O'Neill B, Han DD, Gu HH (2009). Cocaine does not produce reward in absence of dopamine transporter inhibition. Neuroreport 20: 9-12.

Volkow ND, Wang GJ, Fowler JS, Logan J, Hitzemann R, Gatley SJ et al (1996a). Cocaine uptake is decreased in the brain of detoxified cocaine abusers. Neuropsychopharmacology 14: 159-168.

Volkow ND, Wang GJ, Fowler JS, Gatley SJ, Ding YS, Logan J et al (1996b). Relationship between psychostimulant-induced "high" and dopamine transporter occupancy. Proc Natl Acad Sci USA 93: 10388-10392.

Volkow ND, Wang GJ, Fowler JS, Logan J, Gatley SJ, Hitzemann R et al (1997). Decreased striatal dopaminergic responsiveness in detoxified cocaine-dependent subjects. Nature 386: $830-833$. 
Willuhn I, Burgeno LM, Groblewski PA, Phillips PEM (2014). Excessive cocaine use results from decreased phasic dopamine signaling in the striatum. Nat Neurosci 17: 704-709.

Yorgason JT, Espana RA, Jones SR (2011). Demon Voltammetry and Analysis software: analysis of cocaine-induced alterations in dopamine signaling using multiple kinetic measures. J Neurosci Methods 202: 158-164.

Zernig G, Ahmed SH, Cardinal RN, Morgan D, Acquas E, Foltin RW et al (2007). Explaining the escalation of drug use in substance dependence: models and appropriate laboratory tests. Pharmacology 80: 65-119.
Zimmer BA, Dobrin CV, Roberts DCS (2011). Brain-cocaine concentrations determine the dose self-administered by rats on a novel behaviorally dependent dosing schedule. Neuropsychopharmacology 36: 2741-2749.

Zimmer BA, Dobrin CV, Roberts DCS (2013). Examination of behavioral strategies regulating cocaine intake in rats. Psychopharmacology 225: 935-944.

Zimmer BA, Chiodo KA, Roberts DCS (2014). Reduction of the reinforcing effectiveness of cocaine by continuous $\mathrm{D}$-amphetamine treatment in rats: importance of active self-administration during treatment period. Psychopharmacology 231: 949-954.

Supplementary Information accompanies the paper on the Neuropsychopharmacology website (http://www.nature.com/npp) 